\title{
Do Choices Affect Preferences? Some Doubts and New Evidence
}

\author{
Steinar Holden
}

CESIFO WORKING PAPER NO. 2868

CAtegory 3: Social Protection

DECEMBER 2009

\footnotetext{
An electronic version of the paper may be downloaded

- from the SSRN website: Www.SSRN.com

- from the RePEc website: Www.RePEc.org

- from the CESifo website: www.CESifo-group.org/wp
} 


\title{
Do Choices Affect Preferences? Some Doubts and New Evidence
}

\begin{abstract}
Recent research is exploring the case for choice-induced changes in preferences using the free-choice paradigm of Brehm (1956). Participants are faced with a choice between items that they have given the same rating of liking, two items at a time, and it is found that an item not chosen in one choice has a lower tendency of being chosen in a subsequent choice. This tendency is interpreted as evidence for choice-induced changes in preferences. I argue that this interpretation of the evidence is invalid. Furthermore, I report a novel experiment in which participants were specifically asked to compare the items, allowing for a consistent interpretation of the evidence. I find no evidence of choice-induced changes in preferences after a choice between items where one was viewed as more attractive than the other, but potentially some weak evidence of changes in preferences after a choice between items viewed as equally attractive.
\end{abstract}

JEL Code: D01.

Keywords: choice-induced changes in preferences, post-decision dissonance, cognitive dissonance, choice, carry-over effects.

Steinar Holden
Department of Economics
University of Oslo
Box 1095 Blindern
Norway-0317 Oslo
steinar.holden@econ.uio.no

November 2009

The author would thank Victoria Halstensen, Åshild Johnsen and Askill H. Halse for their help running the experiment, Tarjei Havnes, Aanund Hylland, Robert V. Kail, Kalle Moene, Geir Overskeid and Åsa Rosèn for helpful discussions/suggestions on the experimental design, participants at a presentation of an earlier version of the paper at Department of Psychology, University of Oslo, for stimulating suggestions, and the children and personnel at the following preschools: Andromeda, Universitetets Barnehage and Blindern Barnestuer for their kind participation. The paper is part of the research activities at the centre of Equality, Social Organization, and Performance (ESOP) at the Department of Economics at the University of Oslo. ESOP is supported by the Research Council of Norway. Earlier versions of the paper have had other titles: "Comment on "The Origins of Cognitive Dissonance" by Louisa C Egan, Laurie R. Santos and Paul Bloom", "Testing for Cognitive Dissonance. Evidence from Children" and "How Prevalent is Post-Decision Dissonance? Some Doubts and New Evidence". 


\section{Introduction}

There is a long held view among social psychologist that the choices people make affect their preferences. One possible source of this could be cognitive dissonance (Festinger, 1957). However, when testing for the existence of such an effect, one is faced with the problem that the choices people make usually yield additional information about their preferences. In this case what seems to be a change in preferences, may really just be better measurement of the preferences, without any change. A recent paper Egan, Santos and Bloom (2007), using the free-choice paradigm of Brehm (1956) to test for cognitive or post-decision dissonance among preschoolers, is a case in point. The authors find that when children are repeatedly faced with a choice between items (in this case stickers) that the children previously had given the same rating of liking, two stickers at a time, a sticker that is not chosen in one choice has a lower tendency of being chosen in a subsequent choice against a third sticker. Egan et al interpret this as a change in the attitude toward the unchosen sticker, deeming it less valuable, i.e. as evidence for post-decision dissonance, or, following the terminology of Sagarin and Skowronski (2008), as a psychological carry-over effect.

However, as pointed out independently by Chen (2008) and in a previous version of the current paper (Holden, 2008), this interpretation is problematic. Even if the children have given the two stickers the same rating of liking, it may still be the case that the children prefer one over the other. The fact that a child chooses one sticker over another, provides information that the former sticker is likely to be better than an average sticker with the same rating, while the unchosen sticker is likely to be inferior. Thus, the results do not necessarily imply a change in preferences. In this article I report the results from a modification of the experiment of Egan et al, which is designed to avoid this problem. I find no evidence of a change in preferences after a choice between items where one was viewed as more attractive 
than the other, but some potential evidence of a change in preferences after a choice between items viewed as equally attractive.

\section{A free-choice experiment}

In the experiment of Egan et al, 30 4-year-old children were shown a number of commercially available foam stickers of various shapes. The children were asked to rate the stickers using a smiley-face rating scale with six rating levels, and one identified a number of triads, that is, three stickers that a child had given the same rating. In the next phase, each child was given the choice between two stickers A and B from a triad. Finally, the child was given a second choice between the sticker not selected in the first choice (say B), and the third sticker from the triad, C.

In the experiment, the children chose the novel alternative, $\mathrm{C}$, in $63 \%$ of the cases. This is consistent with the idea that, even if the stickers ex ante were rated as equal, the act of rejecting B lowered its value. However, an alternative interpretation of the results is that the children also prior to the choices have a ranked preference ordering for the stickers, in spite of the stickers having the same rating. A ranked preference could result from the children having a finer preference scale than six levels. Ex ante, there would be six possible rankings of the three stickers: $[A, B, C],[A, C, B],[B, A, C],[B, C, A],[C, A, B],[C, B, A]$. However, a choice of A over B would indicate a prior preference for A over B, which would be inconsistent with the rankings where B is preferred over A. This would leave three possible rankings: $[\mathrm{A}, \mathrm{B}, \mathrm{C}],[\mathrm{A}, \mathrm{C}, \mathrm{B}],[\mathrm{C}, \mathrm{A}, \mathrm{B}]$. We observe that in two of these, $\mathrm{C}$ is ranked above $\mathrm{B}$, implying that there is now a $2 / 3$ probability that $\mathrm{C}$ is preferred to $\mathrm{B}$. Thus, it follows that without any change in preferences, one would expect the participants to prefer the third sticker $\mathrm{C}$ in $2 / 3$ or $66.7 \%$ of the cases, rather close to the experimental outcome from Egan et al's study of $63.0 \%$. 
The intuition here is that while A, B and C are equally attractive in expected terms ex ante, the fact that a child prefers A to B provides new information that A is likely to be somewhat more attractive, and B somewhat less attractive. Thus, participants are likely to prefer A over C (with probability 2/3), and C over B (with probability 2/3), cf. the possible rankings above. This is the basis for the critique in Chen (2008) and Holden (2008).

The critique of Chen (2008) has led to debate (Sagarin and Skowronski, 2009, Chen and Risen, 2009) as well as new experiments designed to avoid the problem. Chen and Risen (in preparation) and Risen and Chen (2009) redesign the experiment so as to circumvent the problem, along the lines suggested in Chen (2008). Egan, Bloom and Santos (2009) consider the effects when the participants choose between objects they cannot see, implying that any effect on subsequent choices cannot be caused by prior preferences between the objects. Egan et al find a clear effect of the participants' first choice on their second, in the sense that the objects rejected in the first choice were less preferred in the second choice, consistent with a carry-over effect.

Egan et al's study is a good illustration of the problems associated with constructing a test which avoids that the choice reflects preferences. On the one hand, Egan et al's proposal is ingenious, as a blind choice clearly ensures that the choice is unaffected by the preferences, thus making a clean test of any carry-over effect. On the other hand, the test is made in a very specific setting, where the participant makes a choice between two objects without any information about their characteristics. It is not clear that a carry-over effect will be the same after a choice where the participant has seen the two objects, and thus made a comparison, as when the choice is made without seeing the objects. Thus, to what extent the result of Egan et al (2009) can be extended to other choice settings remains open. The present paper suggests a different route to explore the issue. 


\section{The novel experiment}

The argument given above is based on the implicit assumption of a perfect ranking of stickers, so that the children always prefer one over another. However, we all know that in some cases it may be difficult to choose between two items, so it is not clear that the children will always have a strict ranking. Thus, I make a small but important departure from the assumption of perfect ranking. I still assume that the children's liking of the stickers can be measured along a continuous scale, so that there in principle is always a perfect ranking. However, I also assume that for each child there is a minimum distance of preference that is necessary for the child to say that one sticker is better than the other. In other words, if the stickers are too close on the scale, the child will be unable to tell which sticker is better. Thus, in an experiment it will be important to allow for the possibility that children are indifferent between two stickers.

43 4- and 5-year-olds participated in the study, 20 girls and 23 boys. Children were recruited from three preschools in the Blindern area, in Oslo, Norway. They were tested in their preschool, while sitting at a desk across from the experimenter.

The children's preferences for different stickers were assessed using a smiley-face rating scale that included five faces, from sad to very happy, corresponding to five levels of liking. ${ }^{1}$ While many of the children already were familiar with smiley-faces as a measure of liking, the experimenter nevertheless ensured that all understood the scale. This was confirmed by appropriate responses to three queries by the experimenter: "Let's say I like a sticker a whole lot/not at all/somewhere in the middle. Which face should I put it with?”

When the children had shown that they understood the rating scale, they were presented with stickers one by one and asked to match to the faces. We used commercially available adhesive foam stickers with various pictures and shapes, like faces, animals, stars,

\footnotetext{
${ }^{1}$ Experience from an earlier experiment suggested that five levels is enough, and that many children had problems with making use of a grading scale with more levels. While this departs from the specification in Egan et al (2007), who use six levels, this was viewed as less important, as the interpretation of the results does not hinge on any comparison with the results of Egan et al (2007).
} 
etc. Most children rated all the 30 stickers presented to them, but 5 became fatigued and stopped earlier. One child rated only two triads, i.e. two times three stickers with the same rating level, while the other children rated at least five triads.

The next phase was conducted by another experimenter, to avoid the children being questioned repeatedly by the same person about their preferences over the same stickers. Each child was given the choice between two stickers, A and B, randomly chosen from a triad. The stickers were put on a plate in front of the child, and the experimenter asked "Do you like these stickers equally much, or do you like one sticker better than the other?” When the child had responded to this question, he or she was asked which of the stickers he or she would like to take home. (Chosen stickers were put in an envelope bearing the child's name, to be taken home at the end of the day.) Next, the child was again presented with two stickers, this time the unchosen alternative (which we refer to as B) and the third sticker in the triad, C. Again, the experimenter asked "Do you like these stickers equally much, or do you like one sticker better than the other?” When the child had responded to this question, he or she was asked which of the stickers he or she would like to take home, and the chosen sticker was put in the envelope. This process continued until the child had chosen between all the triads.

The idea here is that if the children prior to both choices respond that they like one sticker better than the other, then the children have a complete ranking of the stickers, implying that there is a 2/3 probability of choosing the novel sticker $C$ in the second choice. Thus, evidence of a carry-over effect requires that $C$ is chosen in more than $2 / 3$ of the cases. In contrast, if the children respond that they like stickers A and B equally much, then the subsequent choice is assumed to give no information about the preferences over the stickers, and the prior in the second choice is $50 \%$. In this case a choice of $\mathrm{C}$ in more than $50 \%$ of the cases would suggest the existence of a carry-over effect (the interpretation of these tests will be discussed further below). Finally, if the children say that they like one sticker better than 
the other in the first choice, yet they like the stickers equally much in choice two, one would expect the children to choose either of the stickers in the second choice with probability 0.5 . Choosing the novel sticker with a higher probability would suggest that the sticker not chosen in the first choice has become less attractive for the child, even if the child may still claim that they like it as well as the other sticker.

Note that asking the children to compare two specific stickers at a time differs from the approach made in past studies of carry-over effects. The motivation for doing this is to ensure a more accurate measurement of the preferences of the children. In an initial rating of many stickers according to a predefined rating scale, there may be a problem if the children have a finer rating than the scale, or that the children are unable to use the rating scale in a consistent way over time. ${ }^{2}$ If children are asked to rank a number of different items, this may force them to rank items that they find equally attractive. Furthermore, it may be more difficult to rank many items at the same time, rather than comparing just two items.

A potential problem with asking the children to compare two items is that it may affect whether a carry-over effect will take place. In the cases where the children respond that they like sticker A better than sticker B, their response may make them perceive the choice to be an easy choice between two different stickers, in which case no carry-over effect need occur. However, one should recall that the choice is between stickers previously given the same rating, so there should not be a big difference in the liking of the stickers. Much of the previous research on post-decision dissonance examine shifts in ratings or rankings, where one finds an effect of a choice between two closely, but not identically, ranked objects. Note also that the cases where participants respond that they like the stickers equally much, is not subject to this criticism.

\footnotetext{
${ }^{2}$ Chen (2008) points out that in experiments when participants are asked to rerank a number of items, the second ranking is usually not fully consistent with the first.
} 


\section{Results}

In total, the 43 children rated 339 triads, i.e. an average of 8.3 triads. All the children responded at least once that they preferred one sticker to the other in both choices, and this happened for 223 triads, see Table 1, row LL. In these cases the rank argument applies and the expected ratio for the novel sticker $\mathrm{C}$ is $66.7 \%$. The experimental outcome was somewhat lower, $64.6 \%$, with a $95 \%$ confidence interval from $57.9 \%$ to $70.8 \%$. The outcome was not affected by the initial rating of the stickers, being $63.5 \%$ for the most preferred stickers (rating 4 and 5) and 65.3\% for the least preferred (rating 1-3). Thus, there is no indication of a carryover effect, even if the fairly wide confidence interval clearly implies that we cannot rule out that it nevertheless exists.

For 86 of the triads, the child responded that he or she liked the two stickers equally much (Table 1, row EE \& EL). 33 children did this at least once. Thus, in these cases the first choice gave no information of a prior preference of the stickers, and the expected ratio of the third sticker $\mathrm{C}$ in the second choice would hence be $50 \%$. In the experiment, the third sticker C was chosen in 52 of the 86 cases, or $60.5 \%$. The $95 \%$ confidence interval was $49.3 \%$ to $70.1 \%$, and the ratio was above the expected $50 \%$ with a p-value of $6.6 \%$ (binomial distribution, two-sided). Thus, this gives some indication of a carry-over effect after a choice between stickers which the child finds equally attractive.

For these triads, the tendency to choose the novel sticker $C$ depended strongly on the rating. For the two best ratings, sticker $C$ was chosen in $52.1 \%$ of the cases, i.e. very close to the prior of 50\%. However, for the three least-preferred ratings, sticker $\mathrm{C}$ was chosen in $71.1 \%$ of the cases, which is above $50 \%$ with p-value of $1.4 \%$ (binomial, two-sided), and with a $95 \%$ confidence interval from $55.9 \%$ to $86.2 \%$. One might think that the difference could be caused by the children being less inclined to differentiate between the less attractive stickers in the first choice, i.e. responding that they were equal even if the child really preferred one 
sticker and subsequently chose that one. In this case there would be a tendency that the children would prefer the novel sticker for the least preferred ratings, consistent with the results. However, to the contrary it turned out that it was the most-preferred triads that were least likely to be differentiated: For the triads with the two best ratings, the children stated that they liked the stickers equally much in 32\% of the cases, while for the two least-preferred ratings, this only happened in $20 \%$ of the cases. An alternative interpretation of the result is that when the children have once rejected an alternative that they do not find very attractive, this makes them even less likely to choose it in a subsequent choice.

In the remaining 30 triads, the children responded that they preferred one sticker in the first choice, but that they liked the stickers equally well in the second choice (row LE in Table 1). Given this latter information, one would expect that the novel sticker $C$ was chosen in half of the cases. However, it turned out that $\mathrm{C}$ was chosen in $73.3 \%$ of the cases, which is significantly above $50 \%$ with p-value of $1.6 \%$ (binomial, two-sided). Thus, also when the children respond that they like the stickers equally well, there seems to be tendency that they choose the novel sticker. For these stickers the tendency of choosing the novel sticker in choice 2 was stronger for the most preferred stickers, but this was only 8 triads in total.

\begin{tabular}{|c|c|c|c|c|c|c|c|c|}
\hline \multirow[t]{2}{*}{ Table 1} & \multicolumn{2}{|c|}{ Total sample } & \multicolumn{2}{|c|}{$\begin{array}{l}\text { Most preferred } \\
\text { (rating } 4 \text { \& 5) }\end{array}$} & \multicolumn{2}{|c|}{$\begin{array}{l}\text { Least preferred } \\
\text { (rating 1-3) }\end{array}$} & \multicolumn{2}{|c|}{$\begin{array}{l}\text { First triad for the } \\
\text { child }\end{array}$} \\
\hline & Triads & C chosen & Triads & C chosen & Triads & C chosen & Triads & C chosen \\
\hline $\mathrm{LL}$ & 223 & $64.6 \%$ & 96 & $63.5 \%$ & 127 & $65.3 \%$ & 20 & $65.0 \%$ \\
\hline EL \& EE & 86 & $60.5 \% *$ & 48 & $52.1 \%$ & 38 & $71.1 \% * *$ & 16 & $62.5 \%$ \\
\hline $\mathrm{LE}$ & 30 & $73.3 \% * *$ & 8 & $87.5 \% *$ & 22 & $68.2 \%$ & 7 & $57.1 \%$ \\
\hline \multicolumn{9}{|c|}{$\begin{array}{l}\text { LL: Likes one sticker better in both choices; EL: Stickers Equal in first choice, Like one better in second; } \\
\text { etc. } \\
\text { Triads is number of triads, and C chosen is the percentage C is chosen in the second choice } \\
* * \text { denotes significantly different from } 66.7 \% \text { (LL) or } 50 \% \text { (EL, EE, LE) at the } 5 \% \text { level, * at } 10 \% \text { level }\end{array}$} \\
\hline
\end{tabular}

A possible objection to the experiment is that children learn from the course of the experiment that they will be asked to choose between the two stickers, and that this makes 
them less likely to respond that they like the stickers equally much, so as to avoid a potential inconsistency in their behavior. If children report a clear preference also in some cases where they in fact are indifferent, the first choice will provide less information and the expected ratio for sticker $\mathrm{C}$ in the second choice will be biased towards 50\%. Now it is not clear why children should do this, as there is nothing inconsistent in choosing one item when given a choice between two identical items ${ }^{3}$. It seems more likely that as children learn that they will be asked to choose, they become more aware of the difference between the stickers, and thus less likely to say that they like them equally much. If the children become more aware of the differences, the first choice would give more precise information about the preferences of the children, reducing any possible bias in the second choice.

The experiment did indeed show some tendency of changed behavior: for the first triad, the children responded that they liked the stickers equally well in $37 \%$ of the cases, while the ratio for the whole sample was $25 \%$; a difference which is significant with p-value 5\%. However, the key issue of the experiment - the choice of the novel sticker C - did not change much: For the majority of triads, where the children had a clear preference prior to both choices (row LL), C was chosen in $65.0 \%$ of the cases, as compared to $64.6 \%$ for the whole sample. For the triads where the child said Equal in the first choice (row EL \& EE), C was chosen in $62.5 \%$ of the cases, as compared to $60.4 \%$ in the whole sample. For the third type of triads (row LE), the choice of C dropped to $57.1 \%$ from $73.3 \%$ in the whole sample. However, this was only seven of the first triads, and cannot be given much weight.

\footnotetext{
${ }^{3}$ To the contrary - the irrational behavior would be to be unable to choose between identical objects - the reader may recall the paradox in philosophy with Buridan's ass, who placed exactly between two equal haystacks, could not decide which to turn to in his hunger.
} 


\section{Discussion}

The experiment gave no indication of post-decision dissonance or a carry-over effect in the large majority of the decisions, when the children had responded that they preferred one sticker above the other in both choices (row LL). The expected ratio for the novel sticker with constant preferences is $66.7 \%$, while in the experiment the novel sticker was only chosen in $64.6 \%$ of the cases, i.e. no tendency of devaluing the rejected sticker. Note that this interpretation is based on a key assumption that when a child responds that s/he likes one sticker better than another, then s/he chooses the one s/he likes best in the subsequent choice. Now, as pointed out by Sagarin and Skowronski (2009) in their argument against Chen (2008), there is some literature suggesting that choices are often probabilistic, in the sense that options that are slightly better are chosen only slightly more often than options perceived as slightly less valuable, see e.g. Carroll and De Soete (1991). If the children take the sticker they like better with probability less than unity, it is straightforward to show that the expected probability for choosing the third sticker in choice 2, with constant preferences, is less than 2/3. In this case, the experiment cannot be used to detect any carry-over effect. However, as argued by Chen, the experiments in this literature are typically based on situations where the options differ slightly in some objective terms. For example, a participant may choose a lever giving slightly more food than another lever slightly more often. In such situations it is not clear that the participants expect the difference between the choices to be constant over time. In the present case, the participants are asked a simple question of whether they like one sticker better than the other, and they respond positively to this question. It is then hard to understand why they would not choose the sticker that they like better.

In the minority of cases where the children found the stickers in the first choice equally attractive, they chose the novel sticker in the second choice in $60.5 \%$ of the cases. The expected ratio with no tendency of devaluing the rejected sticker is $50 \%$. Thus, this gives 
indication of a carry-over effect with a p-value of $6.6 \%$. In particular, for the triads found least attractive, the children chose the novel sticker in $71.1 \%$ of the cases, indicating a carry-over effect with a p-value of $1.4 \%$. However, this interpretation of the experiment is based on a key assumption that when a child says that two stickers are equally attractive, then this is really the case, and in the subsequent choice the stickers have an equal chance. In contrast, if children say that the stickers are equal also when they think that the difference is negligible, and they then take the one they like better with a probability above 0.5 but below unity, the expected ratio for $\mathrm{C}$ would be between $50 \%$ and $66.7 \%$.Then, the results would involve no evidence of a carry-over effect. While there is reason to give considerable confidence to the children's responses, it is hard to rule out that the children in some cases respond that they like the stickers equally much also when they think that the difference between the stickers is very small. Thus, this evidence for a carry-over effect seems less reliable than the evidence based on the majority of the cases, against a carry-over effect.

Also in the cases were the children preferred one sticker prior to the first choice, and viewed the stickers as equal prior to the second choice (i.e. row LE), there was a clear tendency of choosing the novel sticker: It was chosen in $73.3 \%$ of the cases, above $50 \%$ with p-value 1.6\%. This also supports the existence of a carry-over effect. However, if one puts less trust in the reliability of the children's response that they liked the stickers equally much, the fact that they chose the other sticker in choice 1 would bias the proportion $\mathrm{C}$ up. This would weaken the statistical significance of the result.

Overall, the experiment gives no indication of a carry-over effect after a choice between two stickers given the same rating of liking, but where the child nevertheless responded that he or she liked one better than the other. In the some $25 \%$ of the cases when the choice was between stickers viewed as equally attractive, there is potential evidence of a carry-over effect or post-decision dissonance. While this distinction is consistent with the idea 
of Brehm (1956), that post-decision dissonance is stronger after difficult choices, the latter evidence is based on a strong prior assumption and thus less reliable. There is a need for more experiments to shed light on the robustness of these findings.

\section{References}

Brehm, J.W.(1956). Postdecision changes in the desirability of alternatives. Journal of Abnormal and Social Psychology, 52, 384-389.

Carroll, J.D and G. De Soete (1991). Toward a new paradigm for the study of multiattribute choice behavior. American Psychologist 46, April, 342-351.

Chen, K. (2008). Rationalization and cognitive dissonance: Do choices affect or reflect prefences? Mime, Yale University.

Chen, K. and J.L. Risen (2009). Is choice a reliable predictor of choice? A comment on Sagarin and Skowronski. Journal of Experimental Social Psychology 45, 425-427.

Chen, K. and J.L. Risen (in preparation). On the measurement of cognitive dissonance from choice.

Egan, L.C., Bloom, P., \& Santos, L.R. (2009) Choice-based attitude change minus the choice: Comparative and developmental evidence. Under review at Journal of Experimental Social Psychology. 
Egan, L.C, L.R. Santos and P. Bloom (2007). The origins of cognitive dissonance. Evidence from children and monkeys. Psychological Science, 18, 978-983.

Festinger, L. (1957). A theory of cognitive dissonance. Stanford CA, Stanford University Press.

Holden, S (2008). “Comment on ”The Origins of Cognitive Dissonance” by Louisa C Egan, Laurie R. Santos and Paul Bloom”. Mimeo, University of Oslo.

Risen, J.L. and K. Chen (2009). How choice affects and reflects preferences. Revisiting the free-choice paradigm. (submitted for publication)

Sagarin, B.J. and J.J. Skowronski (2009). The implications of imperfect measurement for free-choice carry-over effects: Reply to M. Keith Chen’s (2008). “Rationalization and cognitive dissonance: Do choices affect or reflect preferences?”. Journal of Experimental Social Psychology 45, 421-423. 


\section{CESifo Working Paper Series}

for full list see www.cesifo-group.org/wp

(address: Poschingerstr. 5, 81679 Munich, Germany, office@cesifo.de)

2805 Christian Lessmann and Gunther Markwardt, Aid, Growth and Devolution, September 2009

2806 Bas Jacobs and Dirk Schindler, On the Desirability of Taxing Capital Income to Reduce Moral Hazard in Social Insurance, September 2009

2807 Hans Gersbach and Noemi Hummel, Climate Policy and Development, September 2009

2808 David E. Wildasin, Fiscal Competition for Imperfectly-Mobile Labor and Capital: A Comparative Dynamic Analysis, September 2009

2809 Johan Eyckmans and Cathrine Hagem, The European Union's Potential for Strategic Emissions Trading through Minimal Permit Sale Contracts, September 2009

2810 Ruediger Bachmann and Christian Bayer, The Cross-section of Firms over the Business Cycle: New Facts and a DSGE Exploration, October 2009

2811 Slobodan Djajić and Michael S. Michael, Temporary Migration Policies and Welfare of the Host and Source Countries: A Game-Theoretic Approach, October 2009

2812 Devis Geron, Social Security Incidence under Uncertainty Assessing Italian Reforms, October 2009

2813 Max-Stephan Schulze and Nikolaus Wolf, Economic Nationalism and Economic Integration: The Austro-Hungarian Empire in the Late Nineteenth Century, October 2009

2814 Emilia Simeonova, Out of Sight, Out of Mind? The Impact of Natural Disasters on Pregnancy Outcomes, October 2009

2815 Dan Kovenock and Brian Roberson, Non-Partisan 'Get-Out-the-Vote' Efforts and Policy Outcomes, October 2009

2816 Sascha O. Becker, Erik Hornung and Ludger Woessmann, Catch Me If You Can: Education and Catch-up in the Industrial Revolution, October 2009

2817 Horst Raff and Nicolas Schmitt, Imports, Pass-Through, and the Structure of Retail Markets, October 2009

2818 Paul De Grauwe and Daniel Gros, A New Two-Pillar Strategy for the ECB, October 2009

2819 Guglielmo Maria Caporale, Thouraya Hadj Amor and Christophe Rault, International Financial Integration and Real Exchange Rate Long-Run Dynamics in Emerging Countries: Some Panel Evidence, October 2009 
2820 Saša Žiković and Randall K. Filer, Hybrid Historical Simulation VaR and ES: Performance in Developed and Emerging Markets, October 2009

2821 Panu Poutvaara and Andreas Wagener, The Political Economy of Conscription, October 2009

2822 Steinar Holden and Åsa Rosén, Discrimination and Employment Protection, October 2009

2823 David G. Mayes, Banking Crisis Resolution Policy - Lessons from Recent Experience Which elements are needed for robust and efficient crisis resolution?, October 2009

2824 Christoph A. Schaltegger, Frank Somogyi and Jan-Egbert Sturm, Tax Competition and Income Sorting: Evidence from the Zurich Metropolitan Area, October 2009

2825 Natasa Bilkic, Thomas Gries and Margarethe Pilichowski, Stay in School or Start Working? - The Human Capital Investment Decision under Uncertainty and Irreversibility, October 2009

2826 Hartmut Egger and Udo Kreickemeier, Worker-Specific Effects of Globalisation, October 2009

2827 Alexander Fink and Thomas Stratmann, Institutionalized Bailouts and Fiscal Policy: The Consequences of Soft Budget Constraints, October 2009

2828 Wolfgang Ochel and Anja Rohwer, Reduction of Employment Protection in Europe: A Comparative Fuzzy-Set Analysis, October 2009

2829 Rainald Borck and Martin Wimbersky, Political Economics of Higher Education Finance, October 2009

2830 Torfinn Harding and Frederick van der Ploeg, Is Norway's Bird-in-Hand Stabilization Fund Prudent Enough? Fiscal Reactions to Hydrocarbon Windfalls and Graying Populations, October 2009

2831 Klaus Wälde, Production Technologies in Stochastic Continuous Time Models, October 2009

2832 Biswa Bhattacharyay, Dennis Dlugosch, Benedikt Kolb, Kajal Lahiri, Irshat Mukhametov and Gernot Nerb, Early Warning System for Economic and Financial Risks in Kazakhstan, October 2009

2833 Jean-Claude Trichet, The ECB's Enhanced Credit Support, October 2009

2834 Hans Gersbach, Campaigns, Political Mobility, and Communication, October 2009

2835 Ansgar Belke, Gunther Schnabl and Holger Zemanek, Real Convergence, Capital Flows, and Competitiveness in Central and Eastern Europe, October 2009 
2836 Bruno S. Frey, Simon Luechinger and Alois Stutzer, The Life Satisfaction Approach to Environmental Valuation, October 2009

2837 Christoph Böhringer and Knut Einar Rosendahl, Green Serves the Dirtiest: On the Interaction between Black and Green Quotas, October 2009

2838 Katarina Keller, Panu Poutvaara and Andreas Wagener, Does Military Draft Discourage Enrollment in Higher Education? Evidence from OECD Countries, October 2009

2839 Giovanni Cespa and Xavier Vives, Dynamic Trading and Asset Prices: Keynes vs. Hayek, October 2009

2840 Jan Boone and Jan C. van Ours, Why is there a Spike in the Job Finding Rate at Benefit Exhaustion?, October 2009

2841 Andreas Knabe, Steffen Rätzel and Stephan L. Thomsen, Right-Wing Extremism and the Well-Being of Immigrants, October 2009

2842 Andrea Weber and Christine Zulehner, Competition and Gender Prejudice: Are Discriminatory Employers Doomed to Fail?, November 2009

2843 Hadi Salehi Esfahani, Kamiar Mohaddes and M. Hashem Pesaran, Oil Exports and the Iranian Economy, November 2009

2844 Ruediger Bachmann and Christian Bayer, Firm-Specific Productivity Risk over the Business Cycle: Facts and Aggregate Implications, November 2009

2845 Guglielmo Maria Caporale, Burcu Erdogan and Vladimir Kuzin, Testing for Convergence in Stock Markets: A Non-Linear Factor Approach, November 2009

2846 Michèle Belot and Jan Fidrmuc, Anthropometry of Love - Height and Gender Asymmetries in Interethnic Marriages, November 2009

2847 Volker Nitsch and Nikolaus Wolf, Tear Down this Wall: On the Persistence of Borders in Trade, November 2009

2848 Jan K. Brueckner and Stef Proost, Carve-Outs Under Airline Antitrust Immunity, November 2009

2849 Margarita Katsimi and Vassilis Sarantides, The Impact of Fiscal Policy on Profits, November 2009

2850 Scott Alan Carson, The Relationship between Stature and Insolation: Evidence from Soldiers and Prisoners, November 2009

2851 Horst Raff and Joachim Wagner, Intra-Industry Adjustment to Import Competition: Theory and Application to the German Clothing Industry, November 2009

2852 Erkki Koskela, Impacts of Labor Taxation with Perfectly and Imperfectly Competitive Labor Markets under Flexible Outsourcing, November 2009 
2853 Cletus C. Coughlin and Dennis Novy, Is the International Border Effect Larger than the Domestic Border Effect? Evidence from U.S. Trade, November 2009

2854 Johannes Becker and Clemens Fuest, Source versus Residence Based Taxation with International Mergers and Acquisitions, November 2009

2855 Andreas Hoffmann and Gunther Schnabl, A Vicious Cycle of Manias, Crashes and Asymmetric Policy Responses - An Overinvestment View, November 2009

2856 Xavier Vives, Strategic Supply Function Competition with Private Information, November 2009

2857 M. Hashem Pesaran and Paolo Zaffaroni, Optimality and Diversifiability of Mean Variance and Arbitrage Pricing Portfolios, November 2009

2858 Davide Sala, Philipp J.H. Schröder and Erdal Yalcin, Market Access through Bound Tariffs, November 2009

2859 Ben J. Heijdra and Pim Heijnen, Environmental Policy and the Macroeconomy under Shallow-Lake Dynamics, November 2009

2860 Enrico Spolaore, National Borders, Conflict and Peace, November 2009

2861 Nina Czernich, Oliver Falck, Tobias Kretschmer and Ludger Woessmann, Broadband Infrastructure and Economic Growth, December 2009

2862 Evžen Kočenda and Martin Vojtek, Default Predictors and Credit Scoring Models for Retail Banking, December 2009

2863 Christian Gollier and Martin L. Weitzman, How Should the Distant Future be Discounted when Discount Rates are Uncertain?, December 2009

2864 Tiberiu Dragu and Mattias Polborn, Terrorism Prevention and Electoral Accountability, December 2009

2865 Torfinn Harding and Beata Smarzynska Javorcik, A Touch of Sophistication: FDI and Unit Values of Exports, December 2009

2866 Matthias Dischinger and Nadine Riedel, There's no Place like Home: The Profitability Gap between Headquarters and their Foreign Subsidiaries, December 2009

2867 Andreas Haufler and Frank Stähler, Tax Competition in a Simple Model with Heterogeneous Firms: How Larger Markets Reduce Profit Taxes, December 2009

2868 Steinar Holden, Do Choices Affect Preferences? Some Doubts and New Evidence, December 2009 